\section{Somatoform dissociation, fatigue severity and pain behavior compared in patients with migraine headache and in healthy individuals}

\author{
Ghasem Fattahzadeh-Ardalani, 1 \\ Vida Aghazadeh,2 Abolfazl Atalu, \\ Vahid Abbasi ${ }^{1}$
}

1Department of Neurology, Ardabil

University of Medical Sciences, Ardabil;

2Young Researchers Club and Elite

Club, Ardabil Branch, Islamic Azad

University, Ardabil, Iran

\begin{abstract}
The prevalence of migraine in the world is about 15 and $7 \%$ among women and men, respectively. The purpose of this study was comparison of somatoform dissociation, fatigue severity and pain behavior in patients with migraine headache and its relationship with coping strategies. This descriptive analytical study has been done on 120 patients with migraine headache and 120 healthy subjects were selected randomly. Data collected by somatoform dissociation questionnaire (SDQ-20), fatigue severity scale, pain behavior scale and coping strategies scale. For data analysis we used SPSS.19. The means of the somatoform dissociation, pain behavior scale, help searching subscale and pain compliant in migraine and healthy subjects were statistically significant. There was not significant difference in avoidance subscales between the two groups. Comparison of fatigue severity in patients with migraine and control group was meaningful. There was significant positive correlation between all four scales and coping strategies. It seems that these symptoms can play an important role in this disease; thus, their careful evaluation in the treatment of migraine headache is essential.
\end{abstract}

\section{Introduction}

Migraine is an occasional headache disorder which was determined by different neurological, gastrointestinal symptoms and changes in autonomic nervous. Its diagnosis is based on specifications and symptoms. Results obtained from clinical examinations, like those of laboratory tests, often seem normal. The prevalence of migraine in the world is about 15 and $7 \%$ among the women and men, respectively. On average, about 12 percent of people in Iran are struggling with migraine. Migraine in women is about 2.5 to 3 times more than men. Migraine can begin at any age, although its spread is more during puberty and middle age. ${ }^{1}$ Migraine pain is often pulsating, oneway and on the forehead-temporoparietal area and in most cases it is associated with anorexia, nausea and sometimes vomiting, photophobia, and a feeling of fatigue. Sometimes migraine headache is severe and disrupts the patient's daily activities. Migraine attacks often cause intolerance of light. $^{2}$

Most migraine attacks in women happen from teens to menopause during the hormonal activity. It seems that fluctuations in hormones are involved in creation of the headaches more than the presence of hormones themselves. ${ }^{3}$ Most probably, migraine has a biological - and not a single (mental) - cause. Cognitive factors such as too much attention to the potential pain and fear of re-injury can increase the perception of pain, while psychological factors associated with poor treatment response may not include disaster and inappropriate ways of coping with. ${ }^{4}$ Part of the problems related to migraine is created by psychiatric disasters that are associated with it. Cognition of disorders associated with migraine, can be used in diagnosis and treatment of migraine disease. 5 Many studies have been done on the biological, environmental, psychological and social effects on headache attacks. Results obtained from the studies confirm the relationship between these stimulants and migraine headaches. ${ }^{6}$ Some of the common triggers that have been reported are stress, hunger and fatigue. 7 In syndromes that are known as psychosomatic disorders emotional and psychological factors are associated with their creation. Health problems in psychosomatic theory come from prevention and deterrence of important thoughts and feelings. ${ }^{8}$ Psychosomatic symptoms are numbness, forgetfulness and passivity. The term psychosomatic disorder is used when persons have physical and psychological symptoms, and these symptoms have mainly been created or intensified by psychological factor. The emergence of psychosomatic disorders depends on simultaneous link between psychological factors and physical symptoms with each other. ${ }^{9}$ It seems that chronic pain and fatigue have mental and physical components. Severity of chronic pain and fatigue and components is of great importance. Chronic fatigue is defined as: lack of physical or mental energy that lead to the stop in individuals' activities; sometimes patients use the word fatigue to express the feeling of drowsiness, depression, weakness and
Correspondence: Ghasem FattahzadehArdalani, Department of Neurology, Ardabil University of Medical Sciences, Daneshgah st., Ardabil, Iran.

Tel: +984533513777 .

E-mail: g.fattahzadeh2015@gmail.com

Key words: Somatoform dissociation; Fatigue intensity; Pain behavior; Migraine.

Contributions: GF-A, design and analysis data, clinical visit of samples, write paper; VA and VA, data collected and interview with patients; AA, design and clinical examination of patients and register necessary data for patients in the checklists.

Conflict of interest: the authors declare no potential conflict of interest.

Ethical approval: this study was financially supported by Ardabil Azad University of Medical Science and approved by the University Ethical Committee.

Acknowledgments: the result of this study was financially supported by the research unit of Ardabil University Medical Science and we thank all people who helped us.

Received for publication: 27 December 2016 Revision received: 14 April 2017.

Accepted for publication: 22 April 2017.

This work is licensed under a Creative Commons Attribution NonCommercial 4.0 License (CC BY-NC 4.0).

(C) Copyright G.F.-A. et al., 2017

Licensee PAGEPress, Italy

Neurology International 2017; 9:7015

doi:10.4081/ni.2017.7015

helplessness. Pain is the most common mental stress encountered with individuals and none of other physical symptoms, is not the same extent as pain. ${ }^{10}$

Cavernous sinus (CS) dural arteriovenous fistula (dAVF) patients presenting with only headache as an initial symptom are not and most of patients could induce both types of headache, a migraine and common headache. ${ }^{11}$

Strategies for coping with the disease are cognitive and behavioral responses in an effort to fight the disease. These three strategies are: i) active behavioral approach: patient tries to change some aspects of the disease by active concepts such as using relaxation techniques and regular consultation with the doctor; ii) active cognitive method: patient tries to understand the disease and accept its effect on different aspects of the life by focusing on the positive effects; iii) avoidance method: The patient keeps herself/himself away from 
others, tries to hide her/his feeling of the tension and does not accept thinking about the disease. ${ }^{11}$ Psychological factors associated with migraine disorder affect the therapeutic approaches. As is has been stated in the text Fatigue, pain severity, somatoform dissociation, and coping strategies can have a role in treatment approaches. Using proper tackling techniques helps people with migraine to deal with the issue more effectively. 4

Generally, suffering the migraine affects the life of the person with it for tens of years and even it may affect him/her for more than 60 years together with great pain. In addition to disorders that appear in a person with migraine during the attack of migraine headache, migraine causes disorders in the life quality, reduction in efficiency and reduction of business activities. ${ }^{2}$ Useful time lost in case of people with migraine is considerable and economically irrecoverable. For example, according to the official announcement, financial burden of migraine headaches in America amounts more than 22 billion dollars per year. Also, in other countries this figure has been very heavy in proportion to population and economic situation. A large part of this cost puts pressure on the shoulders of families of the patients. ${ }^{2}$

Thus, instead of bickering between enforcement of potential medical and psychological approaches for the treatment of migraine headaches, it seems reasonable to use both approaches in treatment. Therefore, the purpose of present research is comparing psychosomatic analysis, fatigue severity, pain treatment in patients with migraine headaches and healthy people, and it relation with strategies for tackling with the disease.

\section{Materials and Methods}

This is a descriptive analytical study with post-event and correlation nature. Statistical population of the research was all patients with migraine headaches. The number of participants was 120 patients with migraine headache that were selected by available sampling; also 120 people were chosen as healthy ones. Accordingly, individuals were studied according to the inclusion criteria at the data-gathering period of time (9 months). Inclusion criteria for this study were: diagnosis of migraine headaches, minimum education high school diploma, age 15 to 60 . Exclusion criteria included: suffering from other types of headaches such as: sinusoidal or tensional headaches, suffering from other physical ailments, and illiteracy. Urological clinic of Alavi Hospital in Ardabil city was the place of research.

In order for data collection 4 questionnaire were used, which are as follows.

First, Somatoform Dissociation Questionnaire (SDQ-20): psychosomatic analysis questionnaire was built by Nijenhuis and colleauges in 1996 to assess the severity of psychosomatic symptoms. This scale has been designed with 20 expressions to assess the severity of psychosomatic symptoms that are generally seen in dissociative disorders. These symptoms are numbness, forgetfulness and passivity. A shorter version of this tool, can be used for initial clinical screening. ${ }^{12}$

Second, fatigue severity scale: fatigue severity scale has been developed by Krupp et al. (1989) and is answered in the sevenpoint form; the subject expresses the amount of his/her agreement with each matter by selecting one of the numbers beginning from 1 (strongly disagree) to 7 (quite agree). Items of this scale were selected for identifying common characteristics of fatigue in patients. In Krupp's et al. research (1989) obtained scores were indicatives of considerable significance (95\%). This 7-subject questionnaire has a high degree of internal consistency. The obtained Cronbach's alpha coefficient was 0.86 .13

Third, Pain Behavior Questionnaire: pain behavior questionnaire has been developed by Zarkowska (1981). This test raises certain activities that patients with pain often do them and includes 49 matters that evaluate the three areas of avoidant behaviors, physical complaint and asking for help. Studying the reliability and validity of the test is indicative of its high coefficients. In a research, Reliability coefficients of $0.81,0.78$ and 0.80 were obtained for subscales of avoidance, physical complaint and asking for help, respectively. ${ }^{14}$

Fourth, Questionnaire of Coping Strategies: questionnaire of coping strategies has been maked in 1971. This questionnaire has 43 matters. Namir et.al. (1971) reported the reliability of this questionnaire by Cronbach's alpha coefficient higher than 0.90 .11

In intended research an interview was individually conducted with each one of the individuals diagnosed with migraine disorder. Interviewers were selected from physicians who were unaware of the research process (double-blind). After obtaining written consent from the patients for voluntarily participating in this research, all four questionnaires (questionnaires of psychosomatic analysis, fatigue severity scale, pain treatment, coping with the disease) com- pleted for all samples. To compare the mean scores of variables in migraine patients and healthy subjects, we used descriptive and inferential statistics in SPSS version 19.

\section{Results}

Difference in average score of somatoform dissociation in patients with migraine and healthy people was significant (3.04 vs 22.83, $\mathrm{P}=0.001)$. Also, among the pain treatment scales, asking for help subscales and complaining of pain in patient group respectively with average scores of $\mathrm{M}=32.04$ and $\mathrm{M}=7.47$, and healthy group with the average scores of respectively $\mathrm{M}=22.83$ and $\mathrm{M}=5.38$, there was significant differences. Preventive subscale between the two groups did not have significant differences. Fatigue severity in migraine patients and healthy group had significant differences $(\mathrm{P}=0.001)$. In fatigue severity, the mean score for migraine patients and healthy group are $\mathrm{M}=40.6$ and $\mathrm{M}=33.4$, respectively. In case of strategies for coping with the disease, both preventive and cognitive subscales had significant differences $(\mathrm{P}=0.001)$ (Table 1).

Studies showed that there was not any significant relationship in fatigue severity, with strategies for coping with the disease in migraine patients. In subscales of pain treatment, asking for help had a positive relationship. Also, somatoform dissociation had significant and positive relationship with cognitive subscale in coping with strategies in migraine patients $(\mathrm{P}<0.05)$ (Table 2). All three subscales of pain treatment had significant relationship with subscales of strategies for coping with the disease in healthy people $(\mathrm{P}<0.05)$. Fatigue severity had not a significant relationship with strategies of coping with the disease in healthy people. Somatoform dissociation had significant and positive relationship with protective subscale in the strategies of coping with the disease (Table 3 ).

\section{Discussion}

As shown in the findings, the average of somatoform dissociation in patients with migraine is more than that of healthy people (32.1 vs 22.8). Findings obtained from the present research are aligned with results obtained from similar studies conducted in the field. Consistent with the present study, results obtained from review findings showed that migraine is in a high comorbidity with some psychiatric disorders, and this indicates that patients with migraine 
headache show different kinds of dissociative symptoms including numbness, forgetfulness and indetermination from themselves. ${ }^{15}$ Also in some researches during the investigations among patients with migraine headache and people with tension headaches and comparing it with healthy individuals, the scale of Somatoform dissociation in patients with migraine and tension headache has been significant and they had a high average.16 Study done in the field of other disorders, such as anorexia nervosa and bulimia nervosa, showed Strong relationship with Somatoform dissociation. ${ }^{17}$ These reports show increase in psychosomatic analysis of factors among patients with migraine and other symptoms associated with psychiatric disorders.

Also, in studying the ache, asking for help subscale, and complain of ache in patient group behaviors it became clear that they had high averages compared with those of control group; and among the two groups there were not any significant differences concerning the avoidance subscale Consistent with the results of this research, during the investigations it appears that although migraine is a physiological disease, psychological factors have significant roles in pain management. ${ }^{10}$ In a survey

Table 1. Comparing psychosomatic analysis, pain treatment, fatigue severity and strategies of coping with the disease between patients and healthy group.

\begin{tabular}{|c|c|c|c|c|c|c|}
\hline Variable & Group & Mean & T value & DF & SD & $\mathbf{P}$ \\
\hline Somatoform dissociation & $\begin{array}{l}\text { Healthy people } \\
\text { Patients }\end{array}$ & $\begin{array}{l}22.83 \\
32.04\end{array}$ & 7.761 & 237 & $\begin{array}{c}5.86 \\
12.05\end{array}$ & $<0.001$ \\
\hline Help-seeking subscales & $\begin{array}{l}\text { Healthy people } \\
\text { Patients }\end{array}$ & $\begin{array}{l}22.83 \\
32.04\end{array}$ & 3.359 & 238 & $\begin{array}{l}2.59 \\
1.91\end{array}$ & $<0.001$ \\
\hline Avoidance subscale & $\begin{array}{l}\text { Healthy people } \\
\text { Patients }\end{array}$ & $\begin{array}{l}10.04 \\
15.23\end{array}$ & 4.926 & 235 & $\begin{array}{l}7.84 \\
8.12\end{array}$ & 0.151 \\
\hline Complained of pain subscale & $\begin{array}{l}\text { Healthy people } \\
\text { Patients }\end{array}$ & $\begin{array}{l}5.38 \\
7.47\end{array}$ & 4.905 & 237 & $\begin{array}{l}3.69 \\
2.71\end{array}$ & $<0.001$ \\
\hline Fatigue severity & $\begin{array}{l}\text { Healthy people } \\
\text { Patients }\end{array}$ & $\begin{array}{l}33.39 \\
40.56\end{array}$ & 3.359 & 238 & $\begin{array}{l}12.38 \\
12.15\end{array}$ & $<0.001$ \\
\hline Coping behavioral & $\begin{array}{l}\text { Healthy people } \\
\text { Patients }\end{array}$ & $\begin{array}{l}10.92 \\
14.31\end{array}$ & 5.120 & 237 & $\begin{array}{l}5.24 \\
4.97\end{array}$ & 0.613 \\
\hline Coping cognitive & $\begin{array}{l}\text { Healthy people } \\
\text { Patients }\end{array}$ & $\begin{array}{l}42.14 \\
46.09\end{array}$ & 2.053 & 232 & $\begin{array}{l}17.02 \\
11.83\end{array}$ & $<0.004$ \\
\hline Coping avoidance & $\begin{array}{l}\text { Healthy people } \\
\text { Patients }\end{array}$ & $\begin{array}{l}18.19 \\
21.83\end{array}$ & 3.391 & 236 & $\begin{array}{l}8.19 \\
5.25\end{array}$ & $<0.001$ \\
\hline
\end{tabular}

DF, degree of freedom; SD, standard deviation.

Table 2. Correlation of the strategies of coping with the disease by somatoform dissociation, fatigue severity and pain treatment in patients.

\begin{tabular}{|c|c|c|c|c|c|c|}
\hline $\begin{array}{l}\text { Coping strategies } \\
\text { in patients }\end{array}$ & & Help-seeking & Avoidance & Complained of pain & Fatigue severity & $\begin{array}{l}\text { Somatoform } \\
\text { dissociation }\end{array}$ \\
\hline Behavioral & $\begin{array}{l}\text { Correlation } \\
\text { Significance } \\
\mathrm{N}\end{array}$ & $\begin{array}{c}.302^{* *} \\
.006 \\
119\end{array}$ & $\begin{array}{l}.175 \\
.060 \\
116\end{array}$ & $\begin{array}{c}.256^{* *} \\
.005 \\
118\end{array}$ & $\begin{array}{l}.084 \\
.366 \\
119\end{array}$ & $\begin{array}{l}.089 \\
.348 \\
113\end{array}$ \\
\hline Cognitive & $\begin{array}{l}\text { Correlation } \\
\text { Significance } \\
\text { N }\end{array}$ & $\begin{array}{l}-.013 \\
.889 \\
114\end{array}$ & $\begin{array}{l}.132 \\
.163 \\
113\end{array}$ & $\begin{array}{l}.112 \\
.239 \\
113\end{array}$ & $\begin{array}{l}.025 \\
.791 \\
114\end{array}$ & $\begin{array}{c}.188^{*} \\
.042 \\
117\end{array}$ \\
\hline Avoidance & $\begin{array}{l}\text { Correlation } \\
\text { Significance } \\
\text { N }\end{array}$ & $\begin{array}{l}.146 \\
115 \\
118 \\
\end{array}$ & $\begin{array}{l}.174 \\
.063 \\
115 \\
\end{array}$ & $\begin{array}{l}.161 \\
.082 \\
117 \\
\end{array}$ & $\begin{array}{l}.154 \\
.096 \\
118\end{array}$ & $\begin{array}{l}.169 \\
.067 \\
118 \\
\end{array}$ \\
\hline
\end{tabular}

Pearson Correlation is significant at the 0/01 level (2-tailed**) and 0/05 level (1-tailed*).

Table 3. Correlation results of strategies of coping with the disease by somatoform dissociation, severity of fatigue and pain behavior in control group.

\begin{tabular}{|c|c|c|c|c|c|c|}
\hline $\begin{array}{l}\text { Coping strategies } \\
\text { in healthy people }\end{array}$ & & Help-seeking & Avoidance & Complained of pain & Fatigue severity & $\begin{array}{l}\text { Somatoform } \\
\text { dissociation }\end{array}$ \\
\hline Behavioral & $\begin{array}{l}\text { Correlation } \\
\text { Significance } \\
\text { N }\end{array}$ & $\begin{array}{c}.234^{* *} \\
.010 \\
120\end{array}$ & $\begin{array}{c}.295^{* *} \\
.001 \\
120\end{array}$ & $\begin{array}{c}.297^{* *} \\
.001 \\
120\end{array}$ & $\begin{array}{l}.119 \\
196 \\
120\end{array}$ & $\begin{array}{l}.098 \\
.286 \\
120\end{array}$ \\
\hline Cognitive & $\begin{array}{l}\text { Correlation } \\
\text { Significance } \\
\text { N }\end{array}$ & $\begin{array}{c}.357^{* *} \\
.000 \\
120\end{array}$ & $\begin{array}{c}.399 * * \\
.000 \\
120\end{array}$ & $\begin{array}{c}.428^{* *} \\
.000 \\
120\end{array}$ & $\begin{array}{l}.138 \\
132 \\
120\end{array}$ & $\begin{array}{l}.145 \\
.113 \\
120\end{array}$ \\
\hline Avoidance & $\begin{array}{l}\text { Correlation } \\
\text { Significance } \\
\text { N }\end{array}$ & $\begin{array}{c}.414^{* *} \\
.000 \\
120\end{array}$ & $\begin{array}{c}.340^{* *} \\
.000 \\
120\end{array}$ & $\begin{array}{c}.496^{* *} \\
.000 \\
120\end{array}$ & $\begin{array}{l}.178 \\
.052 \\
120\end{array}$ & $\begin{array}{l}.254^{* *} \\
.005 \\
120\end{array}$ \\
\hline
\end{tabular}


conducted in patients with chronic pain it became clear that seeking for help and accepting the pain had impacts on reduction of factors associated with the severity of the pain. Also, in a study the regression equation regarding the prediction of physical disability showed that, accepting the pain and asking for help factors predicted less physical disability. ${ }^{18}$ And again, an investigation showed that asking for help and pain acceptation, was effective in reduction of pain-related anxiety and the severity of pain. ${ }^{19}$ In a research, Cochran and colleagues to support the multilateral approach to the management of pain behavior used medication and psychological treatments such as relaxation and cognitive behavioral therapy; and they significantly faced with the effectiveness of non-pharmacological treatment in these patients. ${ }^{20}$

The present research showed that the average of severity of fatigue in migraine patients with 40.6 and healthy subjects with 33.4 was significant $(P=0.001)$. In line with the present study, other researches that have been done about pre-sign stages in migraine patients, support fatigue as one of the involved variables at the start of a migraine headache. Also in a report, feeling of fatigue in patients with migraine has been considered as the effects of migraine attacks and it has been confirmed that the patient may feel fatigue or hangover, headache, cognitive problems and weakness. ${ }^{21}$

Results obtained from the present research showed that there were significant and positive relations in all three subscales of strategies of coping with illness with the subscale of seeking for help in ache behavior. Ache severity had not significant relationship with the strategies of coping with illness in migraine patients; psychosomatic analysis had significant relationship with cognitive subscale in strategies for coping with the illness in migraine patients. In healthy subjects, subscales of ache behavior had positive relationship with all the three subscales of coping with strategies. Consistent with the present investigations, a large study in which more than ten thousand subjects participated showed that in studying the behavioral factors in relation to the increased headaches, people with chronic headaches had maladaptive coping with strategies. ${ }^{22}$ Again, a research showed that psychological factors associated with poor treatment response including catastrophizing and the use of maladaptive coping strategies in migraine patients had more averages. ${ }^{23}$ Also, during some other investigations it was shown that the use of maladaptive coping strategies can improve the results obtained from the treatment in people with headaches.

\section{Conclusions}

In explaining the present research it can be said that these psychological factors cause considerable changes in performance, quality of lives of patients, appearance of the next headache attacks, and increase in intensity of ache and fatigue in migraine patients. Therefore, using appropriate coping strategies for management of migraine headaches, adjusting the symptoms of headache disorder, and controlling the disease need more attention by migraine patients accompanied by medical staff.

\section{References}

1. Samaan Z, MacGregor EA, Andrew D, et al. Diagnosing migraine in research and clinical settings: The validation of the Structured Migraine Interview (SMI). BMC Neurology 2010;14:2-7.

2. Ardalani GF, Ghoryshi E, Javani B. Relation between serum magnesium level and severity and frequency of migraine headache attacks. J App Pharm Sci 2016;6:145-7.

3. Furman JM, Balaban CD, Jacob RG, et al. Migraine 2 anxiety related dizziness (MARD): a new disorder? Neurol Neurosurg Psych 2005;1:1-7.

4. Schürks M. Genetics of migraine in the age of genome-wide association studies. J Headache Pain 2012;13:1-9.

5. Robbins MS, Lipton RB. The epidemiology of primary headache disorders. Semin Neurol 2010;30:107-19.

6. Piane M, Lulli P, Farinelli I, et al. Genetics of migraine and pharmacogenomics: some considerations. J Headache Pain 2007;8: 334-9.

7. Bartleson JD, Cutrer FM. Migraine update. Diagnosis and treatment. Minn Med 2010;93:36-41.

8. Levy D, Strassman AM, Burstein R. A critical view on the role of migraine triggers in the genesis of migraine pain. Headache 2009;49:953-7.

9. Kelman L. The postdrome of the acute migraine attack. Cephalalgia 2006;26:21420.

10. Brown H, Newman C, Noad R, et al. Behavioural management of migraine. Ann Indian Acad Neurol 2012;15:S78-S82.

11. Pashapour A, Mohammadian R, Salehpour
F, et al. Long-Term Endovascular Treatment Outcome of 46 Patients with Cavernous Sinus Dural Arteriovenous Fistulas Presenting with Ophthalmic Symptoms. Neuroradiol J 2014;27:461-70.

12. Nijenhuis ERS, Spinhoven P, Van Dyck R, et al. The development and the psychometric characteristics of the Somatoform Dissociation Questionnaire (SDQ-20). J Nervous Mental Dis 1996;184;688-94.

13. Krupp LB, Rocca NG, Steinberg AD. The fatigue scale. J Psychosom Res 1981;31: 147-53.

14. Zarkowska AW. The relationship between subjectine and behavioral aspects in people suffreining from lower back pain. London: University of London; 1981.

15. Antonaci F, Nappi G, Galli F, et al. Migraine and psychiatric comorbidity: a review of clinical findings. J Headache Pain 2011;12: 115-25.

16. Kucukgoncu S, Yildirim Ornek F, Cabalar $\mathrm{M}$, et al. Childhood trauma and dissociation in tertiary care patients with migraine and tension type headache: a controlled study. J Psychosom Res 2014;77:40-4.

17. Espirito-Santo HL, Gonçalves M, Marques $\mathrm{P}$, et al. Correlates of psychoform and somatoform dissociation in eating diosrders. Abstracts of the 21th European Congress of Psychiatry. Eur Psych 2013;28:1.

18. Msgryan F, Asghari-Moghaddam A, barley $M$, et al. Accept the pain in reducing pain and disability in patients with chronic pain. Behav Sci 2012;10:194-203.

19. Nouri M, Ebrahimi A, Neshat H, et al. Effectiveness and acceptance and commitment therapy (ACT) the acceptance of pain, pain-related anxiety and pain in male patients with chronic pain. J Med School Esfahan 2014;259:1-10.

20. Eccleston C, Palermo TM, Williams AC, et al. Cochrane review for paediatric headache: psychological therapies for the management of chronic and recurrent pain in children and adolescents. Cochrane Database Syst Rev 2009;15:CD003968.

21. Kelman L. The postdrome of the acute migraine attack. Cephalalgia 2006;26:21420.

22. Lanteri-Minet $M$, Massiou $H$, NachitOuinekh F, et al. The GRIM2005 study of migraine consultation in France I. Determinants of consultation for migraine headache in France. Cephalalgia 2007;27:1386-97.

23. Lucas C, Lantéri-Minet M, Massiou F, et al. The GRIM2005 study of migraine consultation in France II. Psychological factors associated with treatment response to acute headache therapy and satisfaction in migraine. Cephalalgia 2007;27:1398-407. 